\title{
Retrospective evaluation of endoscopic treatment in colloid cyst of the third ventricle
}

\author{
Krzysztof Stachura, Ewelina Grzywna, Roger M. Krzyżewski, Borys Maria Kwinta \\ Department of Neurosurgery and Neurotraumatology, Jagiellonian University Medical College, Krakow, Poland
}

Videosurgery Miniinv 2021; 16 (3): 604-611

DOI: https://doi.org/10.5114/wiitm.2021.103957

\begin{abstract}
Introduction: Endoscopic methods have gained a well-established position in surgical treatment of colloid cysts of third ventricle. However, the possibility of total tumor removal with this method and the long-term effectiveness of treatment are being questioned.

Aim: Personal twenty years' experience in treatment of third ventricle colloid cysts is presented on the basis of retrospective analysis.

Material and methods: The study group included 58 patients diagnosed by neuroimaging (head CT/MRI) with third ventricle colloid cyst. Post-hospital follow-up ranged from 18 to 42 months. Long-term follow-up head CTIMRI was performed in 39 patients.

Results: The colloid cyst was removed totally in 47 (81\%) patients. In 11 cases, the colloid cyst's wall was tightly adherent to the roof of the third ventricle, which limited the radicality of the procedure. Sixteen patients demonstrated memory impairments, 4 patients epilepsy and another 2 akinetic mutism in the direct postoperative course. One patient died as a result of complications unrelated to the procedure. The average hospitalization was 5 days. In the late period after surgery, remission of the most, previously, reported ailments and symptoms has been reported. Surgical treatment for hydrocephalus was needed in 7 patients. In 3 cases cyst recurrence was diagnosed which required reoperation.

Conclusions: The endoscopic methods allow the total removal of a third ventricle colloid cyst in most patients. Leaving a small coagulated fragment of the cyst rarely results in its recurrence. This method results in effective treatment with a low complications rate, shortens hospitalization time and brings the patient a high level of satisfaction with a quick recovery.
\end{abstract}

Key words: long-term results, neuroendoscopy, colloid cyst, third ventricle.

\section{Introduction}

Colloid cyst of the third ventricle is a benign tumor with its origin in the roof of the ventricle that localizes within its lumen, adjacent to the interventricular foramen. It is most likely of neuroectodermal origin. It comprises a thin collagen wall lined with epithelium and is filled with mucoid brown-green suspension or fluid; rarely its content is solid [1, 2]. By the obstruction of the interventricular foramen of Monro, the colloid cyst may elicit the symptoms of acute obstructive hydrocephalus or even sudden death. Colloid cysts comprise about $0.5-2.0 \%$ of all intracranial tumors [2-4]. The first description of such a cyst comes from 1858 and involves an autopsy finding [5]. In 1921, Dandy performed the

\section{Address for correspondence}

Ewelina Grzywna MD, PhD, Department of Neurosurgery and Neurotraumatology, Jagiellonian University Medical College,

2 Jakubowskiego St, 30-688 Krakow, Poland, phone: +48 12400 2450, fax: +48 12400 2467, e-mail: avafine@gmail.com 
first successful operation of colloid cyst removal [6]. Contemporary surgical modalities include shunting, stereotactic biopsy and microsurgical resection via a transcortical-transventricular, transcallosal or subfrontal approach [7-10]. Recently, there is rising interest in endoscopic methods [2-4, 11-17]. However, the effectiveness of this approach is being discussed. The possibility of cyst recurrence and complications resulting from deep vein damage and fornix and thalamus injury are indicated.

\section{Aim}

The authors aim to present many years' personal experience in endoscopic treatment of colloid cysts of the third ventricle as well as the long-term treatment results.

\section{Material and methods}

This retrospective study included 58 patients with third ventricle colloid cyst diagnosis who were hospitalized in the years 1999-2018, and their full medical records were available. Since year 1999, when the endoscopic approach was implemented into everyday practice in our neurosurgery center, most of the cases have been operated this way. Ta-

Table I. Characteristics of the study group (58 patients with colloid cyst)

\begin{tabular}{|lc|}
\hline Characteristic & $N$ of patients (\% of patients) \\
\hline Sex distribution: & $25(43.1)$ \\
\hline Memale & $33(56.9)$ \\
\hline Age range [years]: & $1(1.7)$ \\
\hline$<20$ & $7(12.1)$ \\
\hline $21-30$ & $15(25.9)$ \\
\hline $31-40$ & $18(31.0)$ \\
\hline $51-50$ & $11(19.0)$ \\
\hline$>60$ & $6(10.3)$ \\
\hline Colloid cyst size [mm]: & $15(25.9)$ \\
\hline$<10$ & $32(55.1)$ \\
\hline $10-20$ & $11(19.0)$ \\
\hline$>20$ & \\
\hline
\end{tabular}

ble I presents the characteristics of the study group. All patients were diagnosed before hospitalization with computed tomography (CT) and/or magnetic resonance imaging (MRI) of the head with contrast enhancement. Symptomatology at admission for all the patients is presented in Table II. In 3 cases the tumor did not result in any neurological symptoms and was diagnosed incidentally in a head CT scan performed due to the head injury. Duration of symptoms ranged from $24 \mathrm{~h}$ to 9 months. In 7 cases it was difficult to determine. Initial diagnostics was expanded in cases where imaging studies had not allowed a detailed assessment of the tumor location in relation to adjacent structures in addition to its tentative character. Since diagnostic uncertainties were present, in 4 cases $\mathrm{CT}$ angiography was performed in order to rule out a possible vascular malformation. The size of tumors qualified for surgical treatment did not exceed $25 \mathrm{~mm}$ in the greatest diameter. The CT density of their content ranged from hypodense to hyperdense. Most cases were accompanied by various degrees of ventricular system enlargement described by the Evans index (Table I). Four patients had external ventricular drainage implanted prior to the endoscopic procedure due to consciousness impairments; in 1 case a ventriculoperitoneal shunt was implanted. This was necessary because of aggravating symptoms of intracranial hypertension and time needed to prepare for surgery.

All patients were operated on under complex intravenous-inhalational general anesthesia. During the procedure the patient's head was positioned in a Mayfield clamp and bent slightly to the chest. The rigid Karl Storz neuroendoscopes were used: Gaab, Frazee and Lotta systems. A $10 \mathrm{~mm}$ burr hole in the lateral precoronal region, usually on the right side, was created in order to gain endoscopic access to

Table II. Clinical symptoms in patients with colloid cysts

\begin{tabular}{|lc|}
\hline Symptoms & N of patients (\% of patients) \\
\hline Headache (positional) & $47(81.0)$ \\
\hline Nausea and vomiting & $31(53.4)$ \\
\hline Dizziness & $17(29.3)$ \\
\hline Gait disturbances & $11(19.0)$ \\
\hline Blurred vision & $8(13.8)$ \\
\hline Short term memory loss & $5(8.6)$ \\
\hline
\end{tabular}


the third ventricle. In selected cases the burr hole location was slightly modified by the configuration of the ventricular system and the location of the colloid cyst. In cases with a narrow ventricular system, stereotactic framework systems were used to determine the optimal trajectory of the surgery, and later - since 2008 - the StealthStation neuronavigation system by Medtronic was introduced. After dura incision and arachnoid coagulation the lateral ventricle was punctured according to the planned trajectory and the lateral ventricle was cannulated. When the endoscope (optics $0,6,30^{\circ}$ ) was placed, the interventricular foramen as well as the caudate laterally and septum medially were identified. Anatomical orientation was facilitated by the choroid plexus passing through the interventricular foramen from the lateral to the third ventricle and septal veinthalamostriate vein angle visible at its lower margin. After the tumor location was identified, feasibility of the intended procedure was analyzed. The wall of the colloid cyst was incised first and its content was aspirated by the polyethylene drain with central and side holes. Then the incision was widened with grasping forceps, and in some cases the more formed part of its content was removed with biopsy forceps. The remaining colloid cyst capsule was separated from the columns of fornix, from the choroid plexus, veins and the roof of the third ventricle and removed in one piece or in fragments. At this stage of the procedure, the lateral canal of the endoscope was helpful, in which flexible gripping tools were placed (Fraziee and Lotta system). The main purpose of the surgery was tumor resection and to unblock the interventricular foremen. The capsule of the colloid cyst was left coagulated, devascularized and widely opened if total removal was associated with risk of bleeding. Bleeding in the operating field was controlled by infusion of Ringer's fluid and coagulation. After colloid cyst was removed, the drain was left in the lateral ventricle to flush the ventricular system with saline. The drain was removed on the first or second postoperative day. Samples resected during surgery were verified histopathologically.

Treatment outcomes were evaluated based on two criteria: clinical and radiological ones. Neurological examination was performed according to commonly accepted protocols and compared to preoperative neurological findings. Radiological evaluation involved either CT or MRI of the head and was assessed by the same team. Radiological criteria of the procedure effectiveness included the lack of recurrence of colloid cyst and regression of hydrocephalus. The first follow-up examination was performed within $48 \mathrm{~h}$ after surgery, before discharge and subsequent examinations 6 months and approximately a year after surgery. Successive late follow-up examinations for the majority of patients were performed annually depending on indications. In part, the late postoperative assessment was conducted during a telephone interview using a questionnaire based on the patient's self-assessment. Post-hospital follow-up ranged from 18 to 42 months (average: 26 months).

\section{Results}

The colloid cyst was removed totally in 47 (81\%) patients. In 11 cases the tight capsule's wall adhesion to the roof of the third ventricle, choroid plexus and venous system affected the radicality of the procedure. Three patients underwent the surgery bilaterally at two different time points because the remnant of the tumor's capsule obstructed the interventricular foramen from the opposite side. In 1 case the endoscopic approach was converted into microsurgical technique because of persistent bleeding. However, no patient required reoperation due to postoperative hemorrhagic complications. Over the years, a relative improvement in resection radicality was noted. The average surgery time was 90 min.

Complications encountered immediately after the surgery in most of the patients were transient. In 16 cases, after colloid cyst removal, memory impairments involving mainly recent memory emerged. In 4 patients seizures were observed. Two patients presented akinetic mutism over a few days. One patient, with multiple comorbidities, died due to complications resulting from deep vein thrombosis of lower extremities. No other neurological deficits, vision disorders, septic/aseptic complications or postoperative impaired wound healing were observed. In follow-up head CT scans performed up to $48 \mathrm{~h}$ after surgery, a small amount of blood was present in the location of the interventricular foramen and/or in the occipital horns of lateral ventricles. However, this was not a reason for any medical intervention. The histopathological diagnosis of neoplasm was achieved in all patients, except 6 - this resulted from the small volume of tested specimens. The average hospitalization lasted 5 days. 
Most patients were free of previously reported ailments and symptoms in long-term follow-up. Memory deficits persisted in 4 patients although they were less severe than immediately after surgery. One patient developed a paroxysmal psychotic syndrome and underwent psychiatric treatment. The late follow-up neuroimaging studies documented the normalization of the ventricular system size and the Evans index, although this did not apply to all cases. The ventricular system remained enlarged to a different extent in 15 patients and it was not related to the radicality of the surgery. In 2 cases ventricular system enlargement developed after surgery. Seven of these patients, presenting symptoms of hydrocephalus within a year after surgery, required surgical intervention. In 2 cases the interventricular foramen was release from adhesions during the endoscopic surgery, and 5 patients received a shunting procedure. In 3 cases in which the colloid cyst was removed incompletely, the lesion has recurred in less than 2.5 years. Two of these patients were reoperated on endoscopically and 1 patient underwent microsurgical reoperation. All studied patients were fully independent after completed neurosurgical treatment. In conversation, they emphasized satisfaction with recovery, with resolution of the previous ailments and quick return to professional activity (Photos 1-3).

\section{Discussion}

The endoscopic approach in the treatment of intraventricular tumors has become widely applicable relatively late, owing to the long domination of microsurgical methods. Initially it was used mostly for tumor biopsy along with so-called assisting neuroendoscopy. In 1983 Powell et al. were the first to report a successful endoscopic aspiration of a colloid cyst of the third ventricle [18]. Indications for surgical treatment of third ventricle colloid cysts have changed over the years. Among 58 patients, upon admission, only in 3 cases did the tumor not cause any neurological symptoms and was a random finding. These patients, however, had radiographic evidence of hydrocephalus due to the presence of a tumor. Asymptomatic colloid cysts have not been operated on.

Colloid cysts, due to their structure along with usually present concomitant obstructive hydrocephalus, seem to be particularly suitable for endoscopic treatment. The purpose of the initial assessment of its feasibility is a thorough analysis of the performed neuroimaging studies. Information on the nature of the lesion arising from the head CT and MRI does not always match the picture encountered in the operative field. The authors experienced such a situation three times when a previously diagnosed cyst turned out to be a glial tumor. Crone highlights the fact that even though a colloid cyst has a characteristic presentation it should be differentiated from a glioma in tuberous sclerosis, subependymoma, craniopharyngioma and rarely from a metastatic tumor [19]. Mathiesen et al. proved that colloid cyst density in a CT image correlates with the viscosity of its content [20]. Hypointensity in T2-dependent MRI images, probably associated with presence of cholesterol esters, may result in difficulties with aspiration during the procedure [21-23].
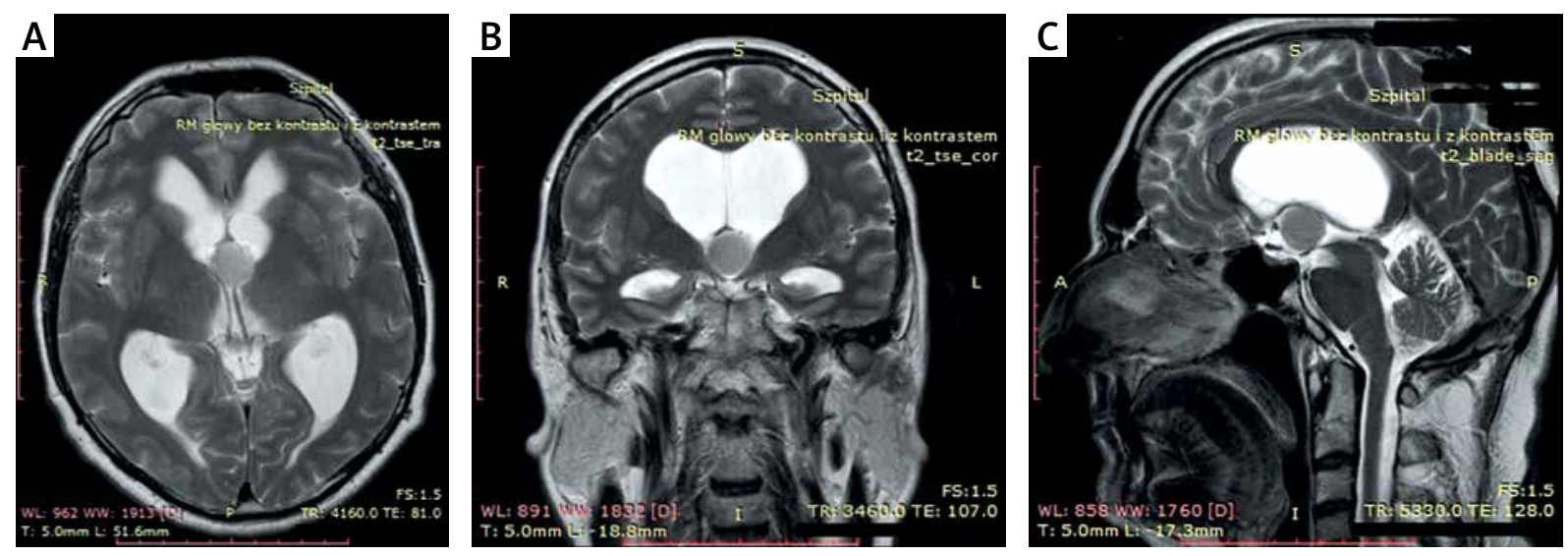

Photo 1. MR (A) axial, (B) coronal and (C) sagittal T2-weighted images: preoperative scans - colloid cyst of the third ventricle 

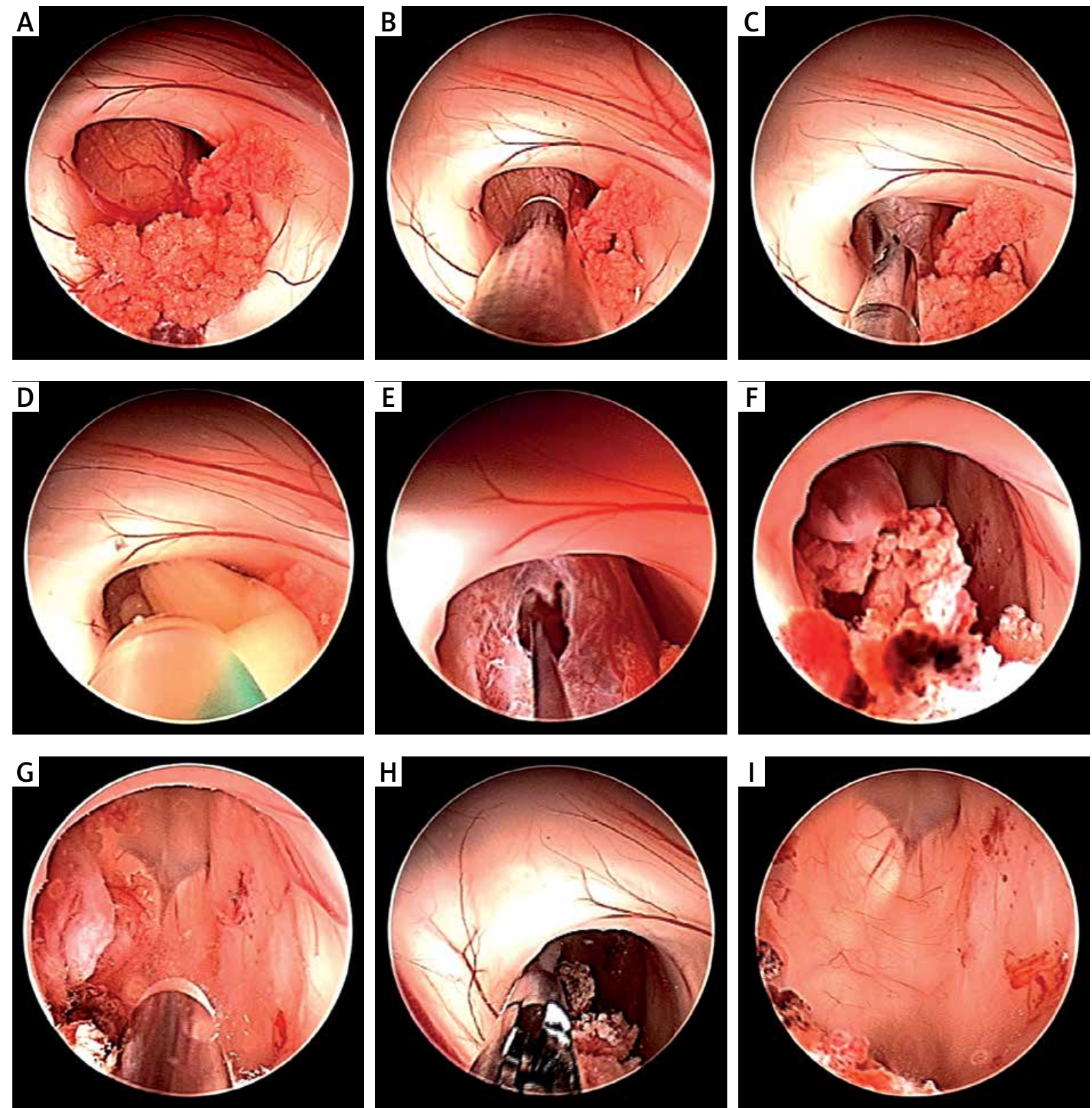

Photo 2. Endoscopic view - stages of endoscopic removal of third ventricle colloid cyst: A - colloid cyst in the interventricular foramen, B - colloid cyst capsule's coagulation, C - colloid cyst capsule's incision, D - colloid cyst content's aspiration, E - colloid cyst capsule's removal, $\mathbf{F}$ - remnants of the colloid cyst capsule, $\mathbf{G}$ - coagulation of the colloid cyst capsule's remains, $\mathbf{H}$ - view after total removal of the colloid cyst capsule, I - view at the third ventricle after total removal of the colloid cyst

Taking into account the $10 \%$ risk of sudden death from acute hydrocephalus due to interventricular foramen obstruction in patients with colloid cyst of the third ventricle, there is no doubt regarding the necessity of surgical treatment. At the same time the purposefulness of radical resection of the lesion is a matter of discussion $[10,14,24]$. The en- doscopic approach limits the size of the resectable part of the colloid cyst up to the width of the working channel of the neuroendoscope. However, no rigid limitations apply in this situation. The operation often imposes a compromise between minimal invasiveness of the surgery and its radicality. Based on the literature, total or gross total resection of the 

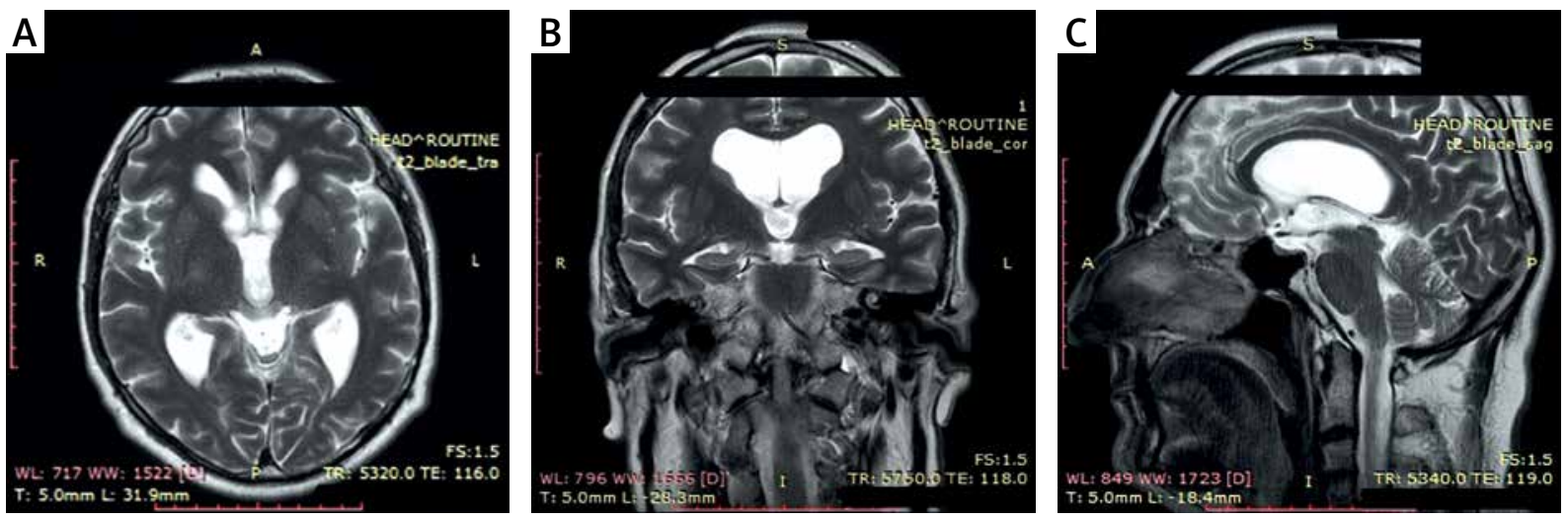

Photo 3. MR axial (A), coronal (B) and sagittal T2-weighted (C) images: postoperative scans - after the endoscopic removal of the colloid cyst of the third ventricle

colloid cyst is feasible in approximately $65 \%$ of cases [17]. The application of 30-degree optics provides a better view into the anatomy of the third ventricle. A recommended step is remodeling of the tumor's capsule by coagulation before its removal. This results in the capsule's shrinkage and facilitates further manipulation. At this stage of the procedure, it is helpful to use flexible instruments inserted into the lateral channels of the endoscope. This requires some proficiency in surgical technique [25]. In the presented material a small fragment of the tumor capsule was left in 11 patients, since the attempts of its removal involved a danger of choroid plexus tear or thalamostriate vein injury. The remaining piece may result in adhesions that obstruct the interventricular foramen, as happened in 2 cases, whereas the extensive capsule resection reduces the risk of recurrence, although opinions on this subject are inconsistent $[26,27]$. Any traction on the capsule should be undeniably avoided for it may cause a difficult to control hemorrhage distant from the operative field. In all cases of unexpected technical difficulties, conversion to microsurgery technique should be considered.

Attentiveness to various aspects of endoscopic treatment of colloid cysts has increased significantly over the past 25 years [2, 3, 11, 13, 15]. Lewis et al. demonstrated the advantages of the endoscopic method, which are minimal brain retraction, perpendicular access trajectory, shorter surgery time, shorter hospitalization and rehabilitation and a complication rate comparable to or even lower than with microsurgical technique [15, 28-32]. Surgery can also be safely performed in patients without concomitant hydrocephalus [33-35]. These observa- tions have also been confirmed in studies focusing on the long-term evaluation of surgery effectiveness $[3,4,17,27,36-38]$. The goal of the endoscopic procedure should be total removal of the colloid cyst, but not at the cost of a potential neurological deficit or disability. On the other hand, the limited radicality of the surgery raises the possibility of colloid cyst recurrence, which occurred in the presented material in 3 cases. Hellwig et al. noted only one recurrence in 20 patients treated endoscopically with subtotal colloid cyst removal, 6 years after surgery. The follow-up in this study ranged from 12 to 117 months [4]. Likewise, Sribrnick et al. reported one late recurrence among 56 operated patients after total cyst removal, observed for an average of 14.9 months. Perioperative mortality was 3.5\% [37]. In a more recent study of the long-term results of colloid cyst endoscopic treatment Vorbau et al. found one asymptomatic late recurrence in the material, in which $80 \%$ radicality was achieved [27]. The radicality of endoscopic surgery improving over time is an expression of the operator's learning curve and also the development of dedicated endoscopes and instruments. The recurrence of the colloid cyst usually is observed in the first 2 years after surgery [17]. Boogaarts et al., based on their studies, have selected a group of patients predisposed to colloid cyst recurrence who need longer follow-up [17]. According to them, residual cysts should be observed in neuroimaging examinations performed at annual intervals. After total resection of the colloid cyst or leaving its remnants, the examination should be performed for up to 2 years. Further follow-up it is less necessary, although cyst recurrence was observed up to 9 years after surgery. 
The most common complications after endoscopic surgery for colloid cyst include memory impairments, aseptic meningitis, transient hemiparesis, epilepsy and late internal hydrocephalus $[4,10$, 17, 39-41]. However, it has been pointed out that neuropsychological symptoms including memory impairment may also result from the mass effect of the colloid cyst on the surrounding anatomical structures [42, 43]. Memory deficits observed in 16 patients were most likely related to injury of the fornix, which most often arises from its traction or contusion. In all these cases the tumor was tightly adherent to the surrounding structures, and in 3 cases the procedure was performed within a narrow ventricular system. In descriptions of similar series the incidence of the memory impairments is estimated to be around $50 \%$ and most often it disappears with time [17, 19, 27, 44-46]. Among the operated patients, no cases of aseptic meningitis were noted. It is considered that it arises from the presence of blood and necrotic tissues within the ventricular system [39]. A meticulous hemostasis along with generous flushing of the operative field should prevent this complication. In cases treated endoscopically it is not always feasible, however. Meningitis is supposed to be prevented with temporary postoperative external drainage of the lateral ventricle; nonetheless, Gaab and Schroeder raise doubts about its effectiveness [14]. Internal hydrocephalus in long-term follow-up, if it does not derive from colloid cyst recurrence, arises from glial membrane formation that obstructs the interventricular foramen on the operation side. One can attempt endoscopic removal of the membrane or it can be evaded through a septostomy occasionally accompanied with third ventriculostomy that creates an alternative route for cerebrospinal fluid circulation $[16,19]$. A custom solution in these cases is shunting.

The high level of patients' satisfaction with the received treatment is meaningful in the overall assessment of the endoscopic method [37].

\section{Conclusions}

The endoscopic approach allows the total removal of the third ventricle colloid cyst in most patients. Leaving remnants of the colloid cyst rarely results in its recurrence. Endoscopic treatment of third ventricle colloid cysts is effective, associated with a low complications rate, shorter hospitalization and enables patients' quick return to professional activity.
The endoscopic method might be recommended as the treatment of choice in third ventricle colloid cyst management.

\section{Conflict of interest}

The authors declare no conflict of interest.

\section{References}

1. Ho KL, Garcia JH. Colloid cysts of the third ventricle: ultrastructural features are compatible with endodermal derivation. Acta Neuropathol 1992; 83: 605-12.

2. Abdou MS, Cohen AR. Endoscopic treatment of colloid cyst of the third ventricle. Technical note and review of the literature. J Neurosurg 1998; 89: 1062-8.

3. Rodziewicz GS, Smith MV, Hodge CJ Jr. Endoscopic colloid cyst surgery. Neurosurgery 2000; 46: 655-62.

4. Hellwig D, Bauer BL, Schulte $M$, et al. Neuroendoscopic treatment for colloid cysts of the third ventricle: the experience of a decade. Neurosurgery 2003; 52: 525-33.

5. Wallman $\mathrm{H}$. Colloid cyst in the third ventricle and lipoma in the plexus choroideus. Virchows Arch 1858; 14: 385-8.

6. Dandy WE. Diagnosis, localization and removal of tumors of the third ventricle. Bull Johns Hopkins Hosp 1922; 33: 188-9.

7. Gutierrez-Lara F, Patino R, Hakim S. Treatment of tumors of the third ventricle: a new and simple technique. Surg Neurol 1975; 3: 323-5.

8. Kondziolka D, Lunsford LD. Stereotactic techniques for colloid cysts: roles of aspiration, endoscopy, and microsurgery. Acta Neurochir 1994; 61 (Suppl): 76-8.

9. Gökalp HZ, Yüceer N, Arasil E, et al. Colloid cyst of the third ventricle. Evaluation of 28 cases of colloid cyst of the third ventricle operated on transcortical/transventricular (25 cases) and transcallosal/transventricular (3 cases) approaches. Acta Neurochir 1996; 138: 45-9.

10. Mathiesen T, Grane P, Lindgren L, Lindquist C. Third ventricle colloid cysts: a consecutive 12-year series. J Neurosurg 1997; 86: 5-12.

11. Caemaert J, Abdullah J, Calliauw L. Endoscopic diagnosis and treatment of para- and intra- ventricular cystic lesion. Acta Neurochir 1994; 61 (Suppl): 69-75.

12. Caemaert J, Abdullah J. Endoscopic management of colloid cysts. Tech Neurosurg 1995; 1: 185-200.

13. Decq P, Le Guerinel C, Brugières P, et al. Endoscopic management of colloid cysts. Neurosurgery 1998; 42: 1288-96.

14. Gaab MR, Schroeder HW. Neuroendoscopic approach to intraventricular lesions. J Neurosurg 1998; 88: 496-505.

15. King WA, Ullman JS, Frazee JG, et al. Endoscopic resection of colloid cysts: surgical considerations using the rigid endoscope. Neurosurgery 1999; 44: 1103-11.

16. Greenlee JD, Teo C, Ghahreman A, Kwok B. Purely endoscopic resection of colloid cysts. Neurosurgery 2008; 62 (Suppl 1): 51-6.

17. Boogaarts HD, Decq P, Grotenhuis JA, et al. Long-term results of the neuroendoscopic management of colloid cysts of the third ventricle: a series of 90 cases. Neurosurgery 2011; 68: 179-87. 
18. Powell MP, Torrens MJ, Thomson JL, Horgan JG. Isodense colloid cysts of the third ventricle: a diagnostic and therapeutic problem resolved by ventriculoscopy. Neurosurgery 1983; 13: 234-7.

19. Crone KR, Miller MN. Colloid cysts: endoscopy vs. microneurosurgical treatment. In: Endoscopy of the Central and Peripheral Nervous System. King W, Frazee J, De Salles A (eds). Thiem, New York Stuttgart 1998; 78-83.

20. Mathiesen T, Grane P, Lindquist C, von Holst H. High recurrence rate following aspiration of colloid cysts in the third ventricle. J Neurosurg 1993; 78: 748-52.

21. Maeder PP, Holtås SL, Basibüyük LN, et al. Colloid cysts of the third ventricle: correlation of MR and CT findings with histology and chemical analysis. AJNR Am J Neuroradiol 1990; 11: 575-81.

22. El Khoury C, Brugières P, Decq P, et al. Colloid cysts of the third ventricle: are MR imaging patterns predictive of difficulty with percutaneous treatment? AJNR Am J Neuroradiol 2000; 21 489-92.

23. Armao D, Castillo M, Chen H, Kwock L. Colloid cyst of the third ventricle: imaging-pathologic correlation. AJNR Am J Neuroradiol 2000; 21: 1470-7.

24. Büettner A, Winkler PA, Eisenmenger W, Weis S. Colloid cysts of the third ventricle with fatal outcome: a report of two cases and review of the literature. Int J Legal Med 1997; 110: 260-6.

25. Wilson DA, Fusco DJ, Wait SD, Nakaji P. Endoscopic resection of colloid cysts: use of a dual-instrument technique and an anterolateral approach. World Neurosurg 2013; 80: 576-83.

26. Hoffman CE, Savage NJ, Souweidane MM. The significance of cyst remnants after endoscopic colloid cyst resection: a retrospective clinical case series. Neurosurgery 2013; 73: 233-7.

27. Vorbau C, Baldauf J, Oertel J, et al. Long-term results after endoscopic resection of colloid cysts. Word Neurosurg 2019; 122: 176-85.

28. Lewis Al, Crone KR, Taha J, et al. Surgical resection of third ventricle colloid cysts. Preliminary results comparing transcallosal microsurgery with endoscopy. J Neurosurg 1994; 81: 174-8.

29. Jeffree RL, Besser M. Colloid cyst of the third ventricle: a clinical review of 39 cases. J Clin Neurosci 2000; 8: 328-31.

30. Desai KI, Nadkarni TD, Muzumdar DP, Goel AH. Surgical management of colloid cyst of the third ventricle: a study of 105 cases. Surg Neurol 2002; 57: 295-304.

31. Stachura K, Libionka W, Moskała M, et al. Colloid cysts of the third ventricle. Endoscopic and open microsurgical management. Neurol Neurochir Pol 2009; 43: 251-7.

32. Margetis K, Souweidane MM. Endoscopic treatment of intraventricular cystic tumors. World Neurosurg 2013; 79 (2 Suppl): $1-11$.

33. Souweidane MM. Endoscopic surgery for intraventricular brain tumors in patients without hydrocephalus. Neurosurgery 2005 57 (4 Suppl): 312-8.

34. Wait SD, Gazzeri R, Wilson DA, et al. Endoscopic colloid cyst resection in the absence of ventriculomegaly. Neurosurgery 2013 73 (1 Suppl): 39-47.

35. Stachura K, Grzywna E. Neuronavigation-guided endoscopy for intraventricular tumors in adult patients without hydrocephalus. Videosurgery Miniinv 2016; 11: 200-7.
36. Kehler U, Brunori A, Gliemroth J, et al. Twenty colloid cysts: comparison of endoscopic and microsurgical management. Minim Invasive Neurosurg 2001; 44: 121-7.

37. Sribnick EA, Dadashev YY, Miller BA, et al. Neuroendoscopic colloid cyst resection: a case cohort with follow up and patient satisfaction. World Neurosurg 2014; 81: 584-93.

38. Samadian M, Ebrahimzadeh K, Maloumeh EN, et al. Colloid cyst of the third ventricle: long-term results of endoscopic management in a series of 112 cases. World Neurosurg 2018; 111: 440-8.

39. Shucart W. Surgical approaches, techniques, and strategies. The anterior transcallosal and transcortical approaches. In: Surgery of the Third Ventricle. Appuzo MJL (ed.). $2^{\text {nd }}$ ed. Williams \& Wilkins, Baltimore 1998; 369-89.

40. Solaroglu I, Beskonakli E, Kaptanoglu E, et al. Transcortical-transventricular approach in colloid cysts of the third ventricle: surgical experience with 26 cases. Neurosurg Rev 2004; 27: 89-92.

41. Grondin RT, Hader W, MacRae ME, Hamilton MG. Endoscopic versus microsurgical resection of third ventricle colloid cysts. Can J Neurol Sci 2007; 34: 197-207.

42. Lobosky JM, Vangilder JC, Damasio AR. Behavioural manifestations of third ventricular colloid cysts. J Neurol Neurosurg Psychiatry 1984; 47: 1075-80.

43. Lajara-Nanson WA. Neuropsychiatric manifestations of a third ventricular colloid cyst. W V Med J 2000; 96: 512-3.

44. Hodges JR, Carpenter K. Anterograde amnesia with fornix damage following removal of IIIrd ventricle colloid cyst. J Neurol Neurosurg Psychiatry 1991; 54: 633-8.

45. McMackin D, Cockburn J, Anslow P, Gaffan D. Correlation of fornix damage with memory impairment in six cases of colloid cyst removal. Acta Neurochir 1995; 135: 12-8.

46. Poreh A, Winocur G, Moscovitch M, et al. Anterograde and retrograde amnesia in a person with bilateral fornix lesions following removal of a colloid cyst. Neuropsychologia 2006; 44: 2241-8.

Received: 2.09.2020, accepted: 9.12.2020. 